\title{
Are prions part of the dark matter of the cell?
}

\author{
Agnès Baudin-Baillieu, ${ }^{\dagger}$ Céline Fabret ${ }^{\dagger}$ and Olivier Namy* \\ University Paris-Sud; Institut de Génétique et Microbiologie; CNRS; Orsay, France
}

†These authors contributed equally to this work.

Key words: prion, yeast, [PSI+] phenotypes, stop codon readthrough, translation termination, amyloid

The $\left[\mathrm{PSI}^{+}\right]$determinant in Saccharomyces cerevisiae is the prion protein corresponding to the eRF3 translation termination factor. Numerous infectious proteins have been described in yeast, in comparison of the unique PrP protein in higher eukaryotes. The presence of the PrP prion is associated with mammalian diseases. Whether fungal prions are beneficial or deleterious are still under discussions. The review focuses on $\left[\mathrm{PSI}^{+}\right]$-induced phenotypes and the resulting physiological consequences to shed light on the cellular changes occurring in a $\left[\mathrm{PSI}^{+}\right]$cell and its possible role in nature. To date, only two genes directly regulated at the translational level by $\left[P S I^{+}\right]$ have been identified. Yet, through all the published works, obtaining a consensus for the described $\left[\mathrm{PSI}^{+}\right]$phenotypes appeared a tricky task. They are highly dependent on the prion variant and the genetic background of the strain. The $\left[\mathrm{PSI}^{+}\right]$prion might generate diverse modifications not only at the translational, but also at the transcriptional levels, and the phenotypic heterogeneity is the result of these complex combinations of the genotypic expression.

The term "prion" was first used by Prusiner" to refer to an infectious protein that does not need an accompanying nucleic acid. This term was used to describe the pathogenic agent of the bovine spongiform encephalopathy, which can be transmitted to humans causing a new variant of the Creutzfeldt-Jacob disease (CJD). These diseases are linked to a conformational conversion of the cellular prion protein $\mathrm{PrP}^{\mathrm{C}}$ into a pathogenic form called $\mathrm{PrP}^{\mathrm{Sc}}$, which is strongly resistant to denaturing reagents. This pathogenic form is believed to propagate by binding to $\operatorname{PrP}^{\mathrm{C}}$ and acting as a template to modify the folding of neo-synthesized $\mathrm{PrP}$ proteins.

The term "prion" was initially used to distinguish the protein-based infectious agent from conventional pathogens. The concept has since been extended to fungi (yeast and filamentous fungus, Podospora anserina) and could probably be extended to many more organisms. Three properties are common to all known fungal prions: (1) Prions display a non-Mendelian segregation and are transmitted through the cytoplasm; (2) The gene encoding the prion protein is necessary for propagation of the prion; (3) once a prion is eliminated from a cell, it may reappear

*Correspondence to: Olivier Namy; Email: Olivier.namy@igmors.u-psud.fr Submitted: 07/31/11; Accepted: 09/29/11

DOI: $10.4161 /$ pri.5.4.18316 spontaneously (due to the presence of the endogenous protein in its soluble form); (4) Prions are self-perpetuating protein conformations.

Yeast prions were first identified as non-Mendelian traits inherited through the cytoplasm. ${ }^{2}$ These prions, called [URE3] and $\left[\mathrm{PSI}^{+}\right]$, arise from self-replicating conformations of proteins encoded by chromosomal genes URE2 and SUP35, respectively. ${ }^{3-6}$ Definitive evidence has been provided by the demonstration that $\left[\mathrm{PSI}^{+}\right]$can be induced by infecting yeast with pure prion protein and that different conformations of stable Sup35 amyloids induce different $\left[\mathrm{PSI}^{+}\right]$variants. ${ }^{7}$ This proof of principle has also been demonstrated with the yeast $[U R E 3]$ and $\left[\mathrm{PIN}^{+}\right]$prions and $P$. anserina [Het-s] prion. ${ }^{8-11}$ Since the discovery of the two initial prions, several new prion proteins have been identified in yeast: Rnqlp/ $\left[P N^{+}\right],{ }^{12,13}$ Swilp, ${ }^{14}\left[G A R^{+}\right],{ }^{15}$ Cyc8p, ${ }^{16}$ Mot3p, ${ }^{17}$ Sfplp ${ }^{18}$ and also Newlp ${ }^{19}$ carrying a prion like domain. More recently, a bioinformatics scan of the yeast genome revealed at least 19 new candidates have a domain that can display prion properties and are therefore strong candidates for additional prions in yeast. ${ }^{17}$ These studies indicate that prion proteins are more frequent than previously anticipated. This raises interesting questions about the physiological relevance of all these prions, as well as the expected number of prions in other organisms such as humans. ${ }^{20}$

Prion formation and maintenance are highly dependent on cellular factors in particular molecular chaperones. ${ }^{21,22} \mathrm{Hsp} 104 \mathrm{p}$ plays a major role in both the generation and propagation of $\left[\mathrm{PSI}^{+}\right] .^{23,24} \mathrm{Hsp} 104 \mathrm{p}$ is involved in protein disaggregation and is required for protein nucleation, the preliminary step before $\left[\mathrm{PSI}^{+}\right]$or [URE3] prion formation. ${ }^{25,26}$ Indeed, one can propose that in vivo the main function of HSP104 is to fragment the large prion aggregate. Evidence is now emerging that even if prions may require similar cellular machinery for their propagation, their sensitivity to molecular chaperones may differ, possibly due to tiny structural differences. ${ }^{27,28}$

$\left[\mathrm{PSI}^{+}\right]$has been one of the most studied prions. Many studies focused on the physiological role of this prion. $\left[P S I^{+}\right]$is the prion form of the eukaryotic release factor 3 (eRF3) a translation termination factor, which, together with eRF1, promotes translational arrest, peptide release and probably ribosome dissociation..$^{29,30}$ The conformational change impairs the termination activity of eRF3, thus increasing stop codon readthrough, and affects mRNA stability [through the "Non-sense mediated decay" (NMD)]. The ability of Sup35p to switch into a prion conformation and the regulation of this switch by the protein remodeling factor Hsp104p have been conserved over a million 
years of fungal evolution. ${ }^{31,32}$ Many phenotypes are associated with the appearance of $\left[\mathrm{PSI}^{+}\right]$and are linked with a defect in termination. ${ }^{33,34}$ However, whether $\left[\mathrm{PSI}^{+}\right]$causes a selective disadvantage or induces phenotype diversity remains unclear. ${ }^{35-37}$ The absence of $\left[\mathrm{PSI}^{+}\right]$in wild yeasts is suggestive of a detrimental role for $\left[\mathrm{PSI}^{+}\right],{ }^{38}$ consistent with a potential defect in translation termination. However, this detrimental function could be counterbalanced by the transient presence of $\left[\mathrm{PSI}^{+}\right]$during stressful periods, facilitating the rapid adaptation of cells in a fluctuating environment. This would be consistent with the conservation of the eRF3 prion domain and of its capacity to switch into a prion conformation over the past one hundred million years. ${ }^{39,40}$ This domain is not required for the termination activity of eRF3; its conservation in distantly related to budding yeast species, such as Candida albicans, Pichia methalonica and Saccharomyces cerevisiae, ${ }^{39,41-43}$ thus suggesting that it fulfils another physiological role. ${ }^{44}$ The $\left[\mathrm{PSI}^{+}\right]$prion may act as a possible evolutionary capacitor based on its positive effect on evolvability ${ }^{45}$ and the fact that its induction/loss frequencies respond to environmental stresses. ${ }^{35,46}$ Nucleotides upstream and downstream from the stop codon have a profound impact on termination efficiency. ${ }^{47,48}$ Thus, in the presence of $\left[\mathrm{PSI}^{+}\right]$, not all termination codons will be subject to readthrough. Indeed, the number of genes affected by the presence of $\left[\mathrm{PSI}^{+}\right]$and the phenotypic consequences are unknown. Numerous attempts to identify an adaptive function of the Sup35p prion state were made by systematic comparison of various phenotypes between several isogenic pairs of $\left[\mathrm{PSI}^{+}\right]$and [psi $i^{-}$strains. True and Lindquist have submitted seven isogenic pairs of strains to more than 150 phenotypic tests. ${ }^{36}$ The growth rate was compared for different carbon or nitrogen sources, and after addition of salts, metals or various inhibitors. Growth at diverse temperatures as well as stress assays (ethanol and thermotolerance) were also analyzed. Indeed, they established that for half growth conditions, at least one $\left[\mathrm{PSI}^{+}\right]$strain behaves differently from the isogenic $\left[p s i^{-}\right]$strain. The spectrum of $\left[P S I^{+}\right]$strain behavior occurs to be wide. It ranges from complete growth inhibition to substantial growth advantage depending on growth conditions and strain genetic background. Interestingly, the presence of $\left[\mathrm{PSI}^{+}\right]$is beneficial in more than $25 \%$ of the conditions tested whereas translation termination deficiency should be deleterious. Another beneficial $\left[\mathrm{PSI}^{+}\right]$advantage might be the expression of essential genes carrying a nonsense mutation, as reported by Lindquist and Kim. ${ }^{49}$ They described a nonsense mutation within the essential HSF1 gene encoding a transcription factor that controls the constitutive expression of heat shock proteins and their heat-induction. The nonsense mutation suppression mediated by $\left[\mathrm{PSI}^{+}\right]$and leading to the production of the fulllength essential protein renders the strain viable. Eaglestone et al. also reported enhanced thermotolerance and chemotolerance for $\left[\mathrm{PSI}^{+}\right]$strains compared with [ $\left.\mathrm{psi}^{-}\right]$strains. ${ }^{35}$ Those studies clearly established that $\left[\mathrm{PSI}^{+}\right]$strains behave differently and that the accompanying phenotypes are in some cases beneficial. Sup35p being a factor involved in translation termination, one might expect that perturbing the translation fidelity in $\left[\mathrm{PSI}^{+}\right]$strains by using antibiotics results in similar phenotypes. Interestingly, no common behavior was observed among the tested strains. ${ }^{36}$
Likewise, the presence of Sup35p aggregates might enhance heat shock protein synthesis and consequently stress tolerance. Once again, no identical responses to stress exposure were reported. In conclusion, the presence of $\left[\mathrm{PSI}^{+}\right]$does not drive identical phenotypes in different strains. Moreover, presence of $\left[\mathrm{PSI}^{+}\right]$can sometimes have opposite consequences on growth of different genetic background cells. This lack of consensus led the authors to propose that genetic background supersede $\left[\mathrm{PSI}^{+}\right]$effect. The molecular basis of this phenotypic diversity can be attributed to stop codon readthrough either individually or in combination with the presence of proteins aggregates or loss/acquisition of other prion proteins (see below). To distinguish between these three causes, mutant strains were constructed and submitted to phenotypic tests. In particular, the impact on translation termination was analyzed by the use of mutations within the C-terminal part of Sup35p altering the termination function. ${ }^{33,35}$ It appeared clearly that the majority of the phenotypes linked to the presence of $\left[\mathrm{PSI}^{+}\right]$were due to decoding of translation termination signals. However, analysis of the progeny arising from crosses between $\left[\mathrm{PSI}^{+}\right]$strains exhibiting a different phenotypic spectrum failed to identify particular molecular targets, as the traits were probably controlled through multiple genetic changes. Nevertheless, it revealed that some traits became independent from $\left[\mathrm{PSI}^{+}\right]$, raising the important question of the fixation of cryptic genetic variations. This study points to the fact that fidelity of translation termination is central to $\left[\mathrm{PSI}^{+}\right]$physiology. Noteworthy, the strain-associated $\left[\mathrm{PSI}^{+}\right]$variant was never analyzed during these studies and the observed phenotype variability might indeed be related to the presence of prions of different strength.

Some candidate genes, which might contribute to the phenotypic diversity, have been identified (Fig. 1). The PDE2 gene, encoding the high-affinity cyclic AMP phosphodiesterase, is subjected to stop codon translational readthrough under the control of $\left[\mathrm{PSI}^{+}\right] .{ }^{50}$ The generated protein harboring a carboxy terminal extension is significantly altered in stability, resulting in increased intracellular cAMP concentration. The cAMP signaling is known to modulate a variety of cellular functions, such as carbohydrate metabolism, cell growth, differentiation, gene transcription and stress responses. ${ }^{51}$ Phosphodiesterases play a key regulatory role, as degradation is the only way to inactivate cAMP. Although PDE2 is not an essential gene in yeast, genetic interactions were revealed with many other genes, which significantly influence stress response, nutrient utilization and the life span of the cell. ${ }^{52}$ Control of PDE2 activity is a critical step for determining intrinsic stress resistance of yeast cells. ${ }^{53}$ Its deletion rendered cells sensitive to freeze-thawing, peroxides, paraquat, cycloheximide, heavy metals, $\mathrm{NaCl}$, heat or cold shock. The decreased translation termination of the PDE2 gene, leading to destabilization of the protein, may account in an unknown extent for a large proportion of the $\left[\mathrm{PSI}^{+}\right]$-dependent phenotypes. Whether this effect is direct or indirect remains to be determined.

The other candidate gene identified as being under the control of $\left[\mathrm{PSI}^{+}\right]$is $O A Z 1$. This gene encodes the ornithine decarboxylase antizyme, described for its regulation of ornithine decarboxylase (ODC) (Fig. 1). ODC is a rate-limiting enzyme in the biosynthesis of polyamines. Polyamines such as spermidine 


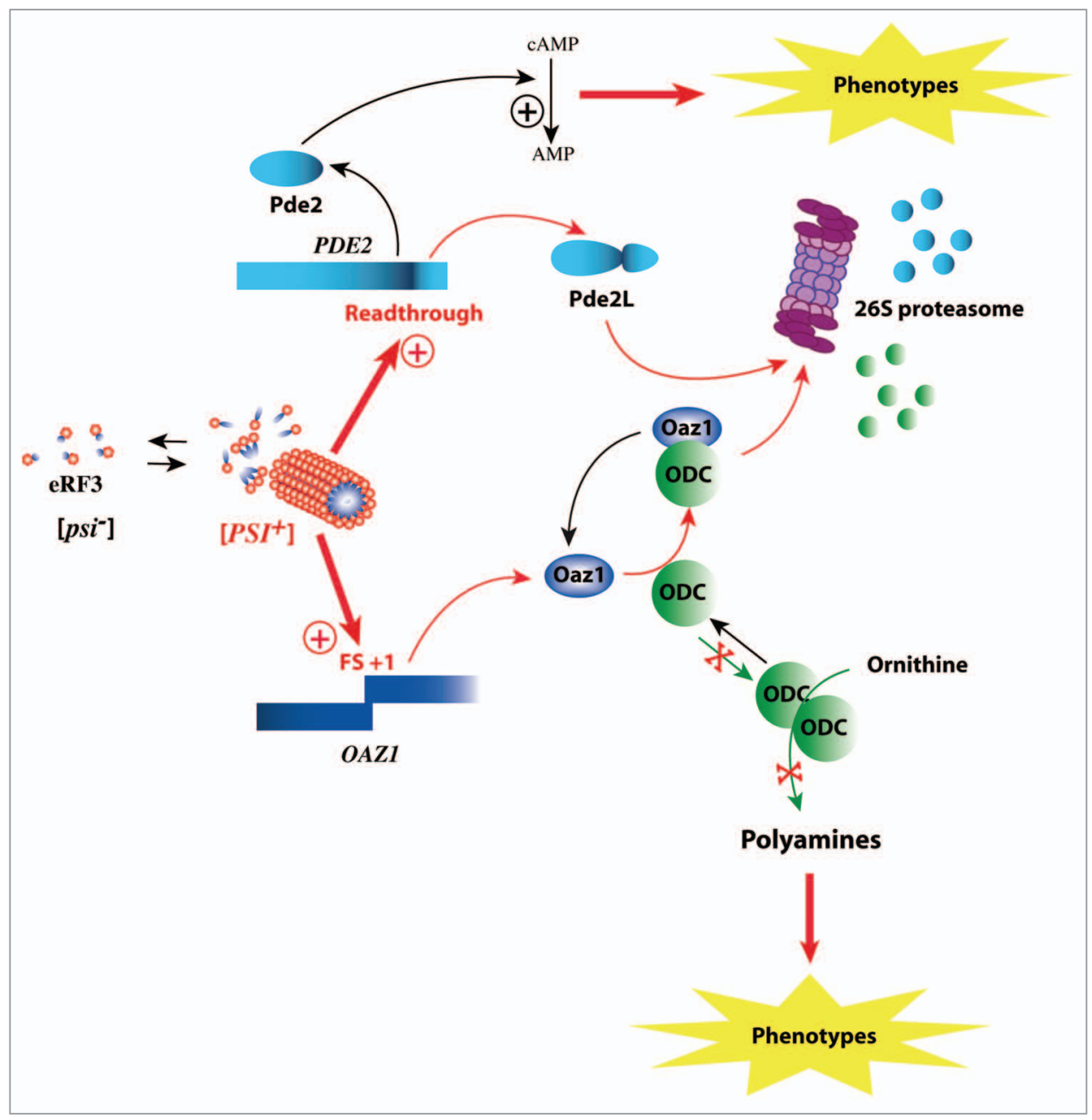

Figure 1. The expression of two genes directly influenced by the prion $\left[P S I^{+}\right]$. The appearance of $\left[P S I^{+}\right]$increases stop codon readthrough efficiency of the PDE2 gene. The longer protein (Pde2L) is rapidly degraded by the proteasome reducing the total amount of Pde2 proteins in the cytoplasm. This leads to a global reduction of CAMP level within the cell resulting in the appearance of several phenotypes. [PSI+] also induces stop codon dependent frameshifting increasing the expression of the antizyme. The increased amount of functional antizyme reduces the overall polyamine concentration. At least half of the $\left[\mathrm{PSI}^{+}\right]$-dependent phenotypes are due to a modification of polyamine content.

and spermine are essential aliphatic organic polycations present in prokaryotes and eukaryotes. They have been implicated in many processes ranging from translation, replication and prion formation to aging. ${ }^{54}$ The antizyme binds to ODC and promotes its ubiquitin-independent degradation via the $26 \mathrm{~S}$ proteasome. ${ }^{55}$ The antizyme levels increase with rising intracellular polyamine concentrations. This process involves the induction of a programmed ribosomal frameshift during decoding of the $O A Z 1$ gene. This programmed frameshifting depends on the presence of a shifty-stop located in the ribosomal A-site during frameshifting. ${ }^{56}$ We recently provided important insight on this issue by demonstrating that a $\left[\mathrm{PSI}^{+}\right]$-induced defect in translation termination stimulates expression of the $O A Z 1$ gene. ${ }^{34}$ The presence of $\left[\mathrm{PSI}^{+}\right]$increases the ribosomal pause at the antizyme shifty-stop, stimulating the production of the protein, which leads to a greater degradation of ODC, and then to a decrease in polyamine levels. In yeast, modification of the cellular content of polyamines by the prion accounts for half of the 22-tested
$\left[\mathrm{PSI}^{+}\right]$-induced phenotypes. This study opens new possibilities for the role of $\left[\mathrm{PSI}^{+}\right]$, which influences cell physiology not only by nonsense codon suppression, but also by modulation of the translational reading frame.

Besides these directly $\left[P S I^{+}\right]$-controlled genes, the change of prion content is also correlated with modifications of the mRNA turnover or the aggregation state of various proteins. Indeed, some $\left[\mathrm{PSI}^{+}\right]$phenotypes can be resumed by inactivation of the NMD RNA helicase Upf1p. ${ }^{33,57}$ The NMD surveillance complex recognizes premature translation termination events and provokes rapid degradation of the mRNA. ${ }^{58}$ Thus, stabilization of NMD mRNA substrates partially explained the $\left[\mathrm{PSI}^{+}\right]$phenotypes. Other investigations suggest a possible impact of prion aggregates-associated proteins. ${ }^{59,60}$ Nevzglyadova et al. identified a large group of such proteins (chaperones, glucose metabolism enzymes, proteins involved in translation and oxidative stress response), whose aggregation may act on the cell physiology and participates to the $\left[\mathrm{PSI}^{+}\right]$phenotypes. 


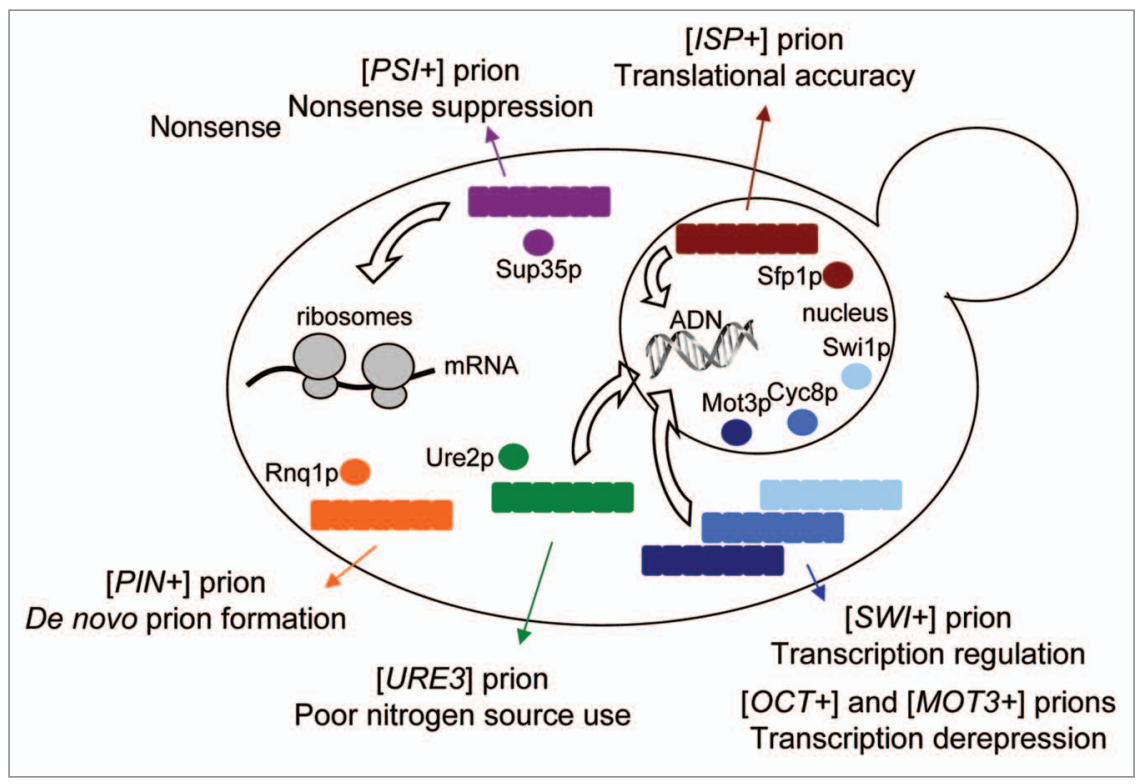

Figure 2. Amyloid-based prions in Saccharomyces cerevisiae. Schematic representation of the soluble and aggregated proteins in the yeast cell. The prion-associated phenotypes and the targeted processes are indicated by colored and white arrows, respectively.

In a same way, the prion state of a protein may influence probability of prionization of another protein, ${ }^{12,61-63}$ which opens a possibility for concerted modification of several proteins at once. Thus the presence of $\left[\mathrm{PSI}^{+}\right]$may induce the appearance of other prions, and the observed phenotypes due to a combination of all. Yet, both mechanisms need do be further established. To date multiple amyloid-based prions have been described in the yeast Saccharomyces cerevisiae (Fig. 2), as well as two self-perpetuating determinants of non-amyloid nature, $[\beta]$ and $\left[G A R^{+}\right] .^{15,64}$

$\mathrm{Du}$ and colleagues ${ }^{14}$ identified the $\left[S W I^{+}\right]$prion linked to the chromatin-remodeling factor Swil. The SWI/SNF complex is evolutionarily conserved and has a regulatory role in gene expression, being responsible for the transcriptional regulation of approximately $6 \%$ of the yeast genome. ${ }^{65}$ Formation of the $\left[S W^{+}\right]$prion results in a partial loss-of-function phenotype for Swil, including poor sporulation and a reduced ability to grow on raffinose as a sole carbon source. Another global transcriptional regulator, the Cyc8 protein is also able to form a prion $\left[O C T^{7}\right]{ }^{16}$ The evolutionarily conserved Cyc8p-Tuplp transcriptional repressor complex controls the expression of over $7 \%$ of yeast genes involved in a wide variety of physiological processes. ${ }^{66}$ Therefore, interplay of both complexes determines the expression fate of many genes by remodeling chromatin in promoter and upstream regions. Thus prionization of $\mathrm{Cyc} 8$ and Swil might have a functional role in creating novel phenotypes.

In a recent genome-wide screen for yeast prion candidates, another globally acting transcription factor, the Mot3p protein, was reported as propagating the $\left[\mathrm{MOT3}^{+}\right]$prion. ${ }^{17}$ The $\left[\mathrm{MOT3}^{+}\right]$ cells exhibit a loss-of-function phenotype for Mot3p, which modulates a variety of processes, including mating, carbon metabolism and stress response. ${ }^{67}$ Moreover further investigations are needed to better specify the phenotypic variations induced after the protein conformational change.
Recently, the $\left[I S P^{+}\right]$prion form of, once again, a global transcriptional regulator, the Sfp1 protein, was demonstrated. ${ }^{18}$ Expression of $-10 \%$ of all yeast genes is positively controlled by Sfp1, including genes that encode ribosomal proteins and other components of the translational machinery. ${ }^{68}$ The Sfp1 prionization causes antisuppression, larger cell size and increased resistance to drugs targeting translation. Interestingly, in contrast to the other known prions, the $\left[I S P^{+}\right]$phenotypes do not correspond to the loss of Sfp1 function. An influence of $\left[I S P^{+}\right]$on the status of some other proteins might be inferred by their prionization or sequestration in aggregates. Another unique feature of this prion is its nuclear location (Fig. 2). These atypical properties of [ISP+] put forward new insights for prion behavior and function within the cell.

Thus numerous prion proteins are positioned at crucial regulatory nodes and could modulate the correlation between genotype and phenotype, as these four known yeast prions corresponding to global transcriptional regulators.

The specific outline of the $\left[\mathrm{PSI}^{+}\right]$phenotypes remains still obscure. Several investigations highlight some modifiers of $\left[\mathrm{PSI}^{+}\right]$ phenotypes, as the Paf1 complex which is involved in mRNA 3 end processing and polyA site selection. ${ }^{69}$ The authors suggest that the Paf1 complex modulates both stability and translatability of some mRNA subjected to $\left[\mathrm{PSI}^{+}\right]$-mediated readthrough. The nonstop mRNA decay (NSD), a process degrading mRNA with no stop codon, was also described as genetically interacting with $\left[P S I^{+}\right] . .^{57}$ Strains defective in NSD show a greater variation in phenotypes between $[p s i]$ and $\left[P S I^{+}\right]$states than corresponding wild-type pairs. These modifiers probably act through mRNA stability and/or translatability and decrease the level of functional C-terminally extended proteins contributing to the phenotype of $\left[\mathrm{PSI}^{+}\right]$strains. Some phenotypes might thus be hidden and under-estimated. 
One way to identify the protein changes induced by the presence of $\left[\mathrm{PSI}^{+}\right]$would be by proteomic approaches. In collaboration with Jean Labarre (CEA Saclay), we subjected total protein extracts of isogenic $\left[p s i^{-}\right]$and $\left[\mathrm{PSI}^{+}\right]$strains to twodimensional gel electrophoreses. Unfortunately no significant difference was observed between the two patterns (personnal communication).

In conclusion, the $\left[\mathrm{PSI}^{+}\right]$phenotypes observed can partially be explained by an effect on the two directly regulated $P D E 2$ and $O A Z 1$ target genes. Moreover the phenotypic heterogeneity might result from the presence of potentially different prion variants and various genetic backgrounds. Focusing on phenotypes certainly helped to better understand the physiological

\section{References}

1. Prusiner SB. Novel proteinaceous infectious particles cause scrapie. Science 1982; 216:136-44; PMID:6801762; DOI:10.1126/science.6801762.

2. Lacroute F. Non-Mendelian mutation allowing ureidosuccinic acid uptake in yeast. J Bacteriol 1971; 106:519-22; PMID:5573734

3. Wickner RB. [URE3] as an altered URE2 protein: evidence for a prion analog in Saccharomyces cerevisiae. Science 1994; 264:566-9; PMID:7909170; DOI: $10.1126 /$ science.7909170.

4. Tuite MF, Cox BS. The [PSI $\left.{ }^{+}\right]$prion of yeast: a problem of inheritance. Methods 2006; 39:9-22; PMID:16757178; DOI:10.1016/j.ymeth.2006.04.001.

5. Doel SM, McCready SJ, Nierras CR, Cox BS. The dominant PNM2-mutation which eliminates the psi factor of Saccharomyces cerevisiae is the result of a missense mutation in the SUP35 gene. Genetics 1994; 137:659-70; PMID:8088511.

6. Paushkin SV, Kushnirov VV, Smirnov VN, TerAvanesyan MD. Propagation of the yeast prion-like [psi $\left.{ }^{+}\right]$determinant is mediated by oligomerization of the SUP35-encoded polypeptide chain release factor. EMBO J 1996; 15:3127-34; PMID:8670813.

7. Tanaka M, Chien P, Naber N, Cooke R, Weissman JS. Conformational variations in an infectious protein determine prion strain differences. Nature 2004; 428:323-8; PMID:15029196; DOI:10.1038/ nature02392.

8. Patel BK, Liebman SW. "Prion-proof" for $\left[\mathrm{PIN}^{+}\right]$: infection with in vitro-made amyloid aggregates of Rnqlp-(132-405) induces [PIN ${ }^{+}$. J Mol Biol 2007; 365:773-82; PMID:17097676; DOI:10.1016/j. jmb.2006.10.069.

9. Brachmann A, Baxa U, Wickner RB. Prion generation in vitro: amyloid of Ure2p is infectious. EMBO J 2005; 24:3082-92; PMID:16096644; DOI:10.1038/ sj.emboj.7600772.

10. King CY, Diaz-Avalos R. Protein-only transmission of three yeast prion strains. Nature 2004; 428:319-23; PMID:15029195; DOI:10.1038/nature02391.

11. Maddelein ML, Dos Reis S, Duvezin-Caubet $S$, Coulary-Salin B, Saupe SJ. Amyloid aggregates of the HET-s prion protein are infectious. Proc Natl Acad Sci USA 2002; 99:7402-7; PMID:12032295; DOI:10.1073/pnas.072199199.

12. Derkatch IL, Bradley ME, Hong JY, Liebman SW. Prions affect the appearance of other prions: the story of [PIN(+)]. Cell 2001; 106:171-82; PMID:11511345; DOI:10.1016/S0092-8674(01)00427-5.

13. Sondheimer N, Lindquist S. Rnq1: an epigenetic modifier of protein function in yeast. Mol Cell 2000, 5:163-72; PMID:10678178; DOI:10.1016/S1097. 2765(00)80412-8.

14. Du Z, Park KW, Yu H, Fan Q, Li L. Newly identified prion linked to the chromatin-remodeling factor Swil in Saccharomyces cerevisiae. Nat Genet 2008; 40:460-5; PMID:18362884; DOI:10.1038/ng.112. consequences of the $\left[\mathrm{PSI}^{+}\right]$prion, nevertheless some specific mechanisms of the de novo appearance or transmission of prions remain still to be elucidated. For example, is $\left[\mathrm{PSI}^{+}\right]$prion useful to reveal cryptic genetic variations and associated phenotypes, or just a by-product of evolution? Overall despite the advances made in the yeast prion field, there are still many questions left unanswered which are part of the future of prion research.

\section{Acknowledgments}

This work is supported by Association pour la Recherche sur le Cancer (ARC; grant No. SFI20101201647), PRES Universud (grant 2010-08).
15. Brown JC, Lindquist S. A heritable switch in carbon source utilization driven by an unusual yeast prion. Genes Dev 2009; 23:2320-32; PMID:19797769; DOI:10.1101/gad.1839109.

16. Patel BK, Gavin-Smyth J, Liebman SW. The yeast global transcriptional co-repressor protein Cyc8 can propagate as a prion. Nat Cell Biol 2009; 11:344-9; PMID:19219034; DOI:10.1038/ncb1843.

17. Alberti S, Halfmann R, King O, Kapila A, Lindquist S. A systematic survey identifies prions and illuminates sequence features of prionogenic proteins. Cell 2009; 137:146-58; PMID:19345193; DOI:10.1016/j. cell.2009.02.044.

18. Rogoza T, Goginashvili A, Rodionova S, Ivanov M, Viktorovskaya O, Rubel A, et al. Non-Mendelian determinant $\left[\mathrm{ISP}^{+}\right]$in yeast is a nuclear-residing prion form of the global transcriptional regulator Sfp1. Proc Natl Acad Sci USA 2010; 107:10573-7; PMID:20498075; DOI:10.1073/pnas.1005949107.

19. Santoso A, Chien P, Osherovich LZ, Weissman JS. Molecular basis of a yeast prion species barrier. Cell 2000; 100:277-88; PMID:10660050; DOI:10.1016/ S0092-8674(00)81565-2.

20. Harrison PM, Gerstein M. A method to assess compositional bias in biological sequences and its application to prion-like glutamine/asparagine-rich domains in eukaryotic proteomes. Genome Biol 2003; 4:40; PMID:12801414; DOI:10.1186/gb-2003-4-6-r40.

21. Jones GW, Tuite MF. Chaperoning prions: the cellular machinery for propagating an infectious protein? Bioessays 2005; 27:823-32; PMID:16015602; DOI:10.1002/bies.20267.

22. Tuite M, Stojanovski K, Ness F, Merritt G, KolotevaLevine N. Cellular factors important for the de novo formation of yeast prions. Biochem Soc Trans 2008; 36:1083-7; PMID:18793193; DOI:10.1042/ BST0361083.

23. Satpute-Krishnan P, Langseth SX, Serio TR. Hsp104dependent remodeling of prion complexes mediates protein-only inheritance. PLoS Biol 2007; 5:24; PMID:17253904; DOI:10.1371/journal. pbio.0050024.

24. True HL. The battle of the fold: chaperones take on prions. Trends Genet 2006; 22:110-7; PMID:16378656; DOI:10.1016/j.tig.2005.12.004.

25. Chernoff YO, Lindquist SL, Ono B, Inge-Vechtomov SG, Liebman SW. Role of the chaperone protein Hsp104 in propagation of the yeast prion-like factor [psi']. Science 1995; 268:880-4; PMID:7754373; DOI:10.1126/science.7754373

26. Shorter J, Lindquist S. Destruction or potentiation of different prions catalyzed by similar Hsp104 remodeling activities. Mol Cell 2006; 23:425-38; PMID:16885031; DOI:10.1016/j.molcel.2006.05.042.
27. Chernoff YO, Newnam GP, Kumar J, Allen K, Zink $\mathrm{AD}$. Evidence for a protein mutator in yeast: role of the Hsp70-related chaperone ssb in formation, stability and toxicity of the [PSI] prion. Mol Cell Biol 1999; 19:8103-12; PMID:10567536.

28. Newnam GP, Wegrzyn RD, Lindquist SL, Chernoff YO. Antagonistic interactions between yeast chaperones Hsp104 and Hsp70 in prion curing. Mol Cell Biol 1999; 19:1325-33; PMID:9891066.

29. Zhouravleva G, Frolova L, Le Goff X, Le Guellec R, Inge-Vechtomov S, Kisselev L, et al. Termination of translation in eukaryotes is governed by two interacting polypeptide chain release factors, eRF1 and eRF3. EMBO J 1995; 14:4065-72; PMID:7664746.

30. Stansfield I, Jones KM, Kushnirov VV, Dagkesamanskaya AR, Poznyakovski AI, Paushkin SV, et al. The products of the SUP45 (eRF1) and SUP35 genes interact to mediate translation termination in Saccharomyces cerevisiae. EMBO J 1995; 14:4365-73; PMID:7556078.

31. Chernoff YO, Galkin AP, Lewitin E, Chernova TA, Newnam GP, Belenkiy SM. Evolutionary conservation of prion-forming abilities of the yeast Sup35 protein. Mol Microbiol 2000; 35:865-76; PMID:10692163; DOI:10.1046/j.1365-2958.2000.01761.x.

32. Zenthon JF, Ness F, Cox B, Tuite MF. The $\left[\mathrm{PSI}^{+}\right]$ prion of Saccharomyces cerevisiae can be propagated by an Hsp104 orthologue from Candida albicans. Eukaryot Cell 2006; 5:217-25; PMID:16467463; DOI:10.1128/EC.5.2.217-25.2006.

33. True HL, Berlin I, Lindquist SL. Epigenetic regulation of translation reveals hidden genetic variation to produce complex traits. Nature 2004; 431:184-7; PMID:15311209; DOI:10.1038/nature02885.

34. Namy O, Galopier A, Martini C, Matsufuji S, Fabret C, Rousset JP. Epigenetic control of polyamines by the prion $\left[\mathrm{PSI}^{+}\right]$. Nat Cell Biol 2008; 10:1069-75; PMID:19160487; DOI:10.1038/ncb1766.

35. Eaglestone SS, Cox BS, Tuite MF. Translation termination efficiency can be regulated in Saccharomyces cerevisiae by environmental stress through a prionmediated mechanism. EMBO J 1999; 18:1974-81; PMID:10202160; DOI:10.1093/emboj/18.7.1974.

36. True HL, Lindquist SL. A yeast prion provides a mechanism for genetic variation and phenotypic diversity. Nature 2000; 407:477-83; PMID:11028992; DOI: $10.1038 / 35035005$.

37. Chernoff YO. Stress and prions: lessons from the yeast model. FEBS Lett 2007; 581:3695701; PMID:17509571; DOI:10.1016/j.febs let.2007.04.075.

38. Nakayashiki T, Kurtzman CP, Edskes HK, Wickner RB. Yeast prions [URE3] and [PSI ${ }^{+}$are diseases. Proc Natl Acad Sci USA 2005; 102:10575-80; PMID:16024723; DOI:10.1073/pnas.0504882102. 
39. Jensen MA, True HL, Chernoff YO, Lindquist S. Molecular population genetics and evolution of a prion-like protein in Saccharomyces cerevisiae. Genetics 2001; 159:527-35; PMID:11606530.

40. Masel J. Cryptic genetic variation is enriched for potential adaptations. Genetics 2006; 172:1985-91; PMID:16387877; DOI:10.1534/genetics.105.051649.

41. Kushnirov VV, Kochneva-Pervukhova NV, Chechenova MB, Frolova NS, Ter-Avanesyan MD. Prion properties of the Sup35 protein of yeast Pichia methanolica. EMBO J 2000; 19:324-31; PMID:10654931; DOI:10.1093/emboj/19.3.324.

42. Nakayashiki T, Ebihara K, Bannai H, Nakamura Y. Yeast $\left[\mathrm{PSI}^{+}\right]$"prions" that are crosstransmissible and susceptible beyond a species barrier through a quasi-prion state. Mol Cell 2001; 7:1121-30; PMID:11430816; DOI:10.1016/S1097-2765(01)00259-3.

43. Resende C, Parham SN, Tinsley C, Ferreira P, Duarte JA, Tuite MF. The Candida albicans Sup35p protein (CaSup35p): function, prion-like behaviour and an associated polyglutamine length polymorphism. Microbiology 2002; 148:1049-60; PMID:11932450.

44. Ter-Avanesyan MD, Kushnirov VV, Dagkesamanskaya AR, Didichenko SA, Chernoff YO, Inge-Vechtomov SG, et al. Deletion analysis of the SUP35 gene of the yeast Saccharomyces cerevisiae reveals two nonoverlapping functional regions in the encoded protein. Mol Microbiol 1993; 7:683-92; PMID:8469113; DOI:10.1111/j.1365-2958.1993.tb01159.x.

45. Masel J, Bergman A. The evolution of the evolvability properties of the yeast prion $\left[\mathrm{PSI}^{+}\right]$. Evolution 2003; 57:1498-512; PMID:12940355.

46. Tyedmers J, Madariaga ML, Lindquist S. Prion switching in response to environmental stress. PLoS Biol 2008; 6:294; PMID:19067491; DOI:10.1371/journal. pbio.0060294.

47. Bonetti B, Fu L, Moon J, Bedwell DM. The efficiency of translation termination is determined by a synergistic interplay between upstream and downstream sequences in Saccharomyces cerevisiae. J Mol Biol 1995; 251:334 45; PMID:7650736; DOI:10.1006/jmbi.1995.0438.

48. Namy O, Hatin I, Rousset JP. Impact of the six nucleotides downstream of the stop codon on translation termination. EMBO Rep 2001; 2:787-93; PMID:11520858; DOI:10.1093/embo-reports/ kve176.

49. Lindquist S, Kim G. Heat-shock protein 104 expression is sufficient for thermotolerance in yeast. Proc Natl Acad Sci USA 1996; 93:5301-6; PMID:8643570; DOI:10.1073/pnas.93.11.5301.

50. Namy O, Duchateau-Nguyen G, Rousset JP. Translational readthrough of the PDE2 stop codon modulates cAMP levels in Saccharomyces cerevisiae. Mol Microbiol 2002; 43:641-52; PMID:11929521; DOI:10.1046/j.1365-2958.2002.02770.x.
51. Thevelein JM, de Winde JH. Novel sensing mechanisms and targets for the cAMP-protein kinase A pathway in the yeast Saccharomyces cerevisiae. Mol Microbiol 1999; 33:904-18; PMID:10476026; DOI:10.1046/ j.1365-2958.1999.01538.x.

52. Poplinski A, Hopp C, Ramezani-Rad M. Ste50 adaptor protein influences Ras/cAMP-driven stress-response and cell survival in Saccharomyces cerevisiae. Curr Genet 2007; 51:257-68; PMID:17318632; DOI:10.1007/ s00294-007-0124-3.

53. Park JI, Grant CM, Dawes IW. The high-affinity cAMP phosphodiesterase of Saccharomyces cerevisiae is the major determinant of cAMP levels in stationary phase: involvement of different branches of the Ras-cyclic AMP pathway in stress responses. Biochem Biophys Res Commun 2005; 327:311-9; PMID:15629464; DOI:10.1016/j.bbrc.2004.12.019.

54. Coffino P. Regulation of cellular polyamines by antizyme. Nat Rev Mol Cell Biol 2001; 2:188-94 PMID:11265248; DOI:10.1038/35056508.

55. Murakami Y, Matsufuji S, Kameji T, Hayashi S, Igarashi $\mathrm{K}$, Tamura $\mathrm{T}$, et al. Ornithine decarboxylase is degraded by the $26 \mathrm{~S}$ proteasome without ubiquitination. Nature 1992; 360:597-9; PMID:1334232 DOI: $10.1038 / 360597 \mathrm{a} 0$

56. Matsufuji S, Matsufuji T, Miyazaki Y, Murakami Y, Atkins JF, Gesteland RF, et al. Autoregulatory frameshifting in decoding mammalian ornithine decarboxylase antizyme. Cell 1995; 80:51-60; PMID:7813017 DOI:10.1016/0092-8674(95)90450-6.

57. Wilson MA, Meaux S, Parker R, van Hoof A. Genetic interactions between $\left[\mathrm{PSI}^{+}\right]$and nonstop mRNA decay affect phenotypic variation. Proc Natl Acad Sci USA 2005; 102:10244-9; PMID:16002465; DOI:10.1073/ pnas.0504557102.

58. Wilusz CJ, Wang W, Peltz SW. Curbing the nonsense: the activation and regulation of mRNA surveillance. Genes Dev 2001; 15:2781-5; PMID:11691829.

59. Bagriantsev SN, Gracheva EO, Richmond JE, Liebman SW. Variant-specific $\left[\mathrm{PSI}^{+}\right]$infection is transmitted by Sup35 polymers within $\left[\mathrm{PSI}^{+}\right]$aggregates with heterogeneous protein composition. Mol Biol Cell 2008; 19:2433-43; PMID:18353968; DOI:10.1091/mbc E08-01-0078.

60. Nevzglyadova OV, Artemov AV, Mittenberg AG, Solovyov KV, Kostyleva EI, Mikhailova EV, et al. Prionassociated proteins in yeast: comparative analysis of isogenic [PSI(+)] and [psi(-)] strains. Yeast 2009; 26:61131; PMID:19774549; DOI:10.1002/yea.1710.
61. Wickner RB, Edskes HK, Roberts BT, Pierce MM, Baxa U, Ross E. Prions beget prions: the [PIN ${ }^{+}$mystery! Trends Biochem Sci 2001; 26:697-9; PMID:11738587; DOI:10.1016/S0968-0004(01)02020-5.

62. Osherovich LZ, Weissman JS. Multiple Gln/Asnrich prion domains confer susceptibility to induction of the yeast $[\mathrm{PSI}(+)]$ prion. Cell 2001; 106:183 94; PMID:11511346; DOI:10.1016/S0092 8674(01)00440-8.

63. Vitrenko YA, Gracheva EO, Richmond JE, Liebman SW. Visualization of aggregation of the Rnq1 prion domain and cross-seeding interactions with Sup35NM. J Biol Chem 2007; 282:1779-87; PMID:17121829; DOI:10.1074/jbc.M609269200.

64. Roberts BT, Wickner RB. Heritable activity: a prion that propagates by covalent autoactivation. Genes Dev 2003; 17:2083-7; PMID:12923060; DOI:10.1101/ gad.1115803.

65. Sudarsanam P, Iyer VR, Brown PO, Winston F. Whole-genome expression analysis of snf/swi mutants of Saccharomyces cerevisiae. Proc Natl Acad Sci USA 2000; 97:3364-9; PMID:10725359; DOI:10.1073/ pnas.050407197.

66. Smith RL, Johnson AD. Turning genes off by Ssn6 Tup1: a conserved system of transcriptional repression in eukaryotes. Trends Biochem Sci 2000; 25:325-30; PMID:10871883; DOI:10.1016/S09680004(00)01592-9.

67. Grishin AV, Rothenberg M, Downs MA, Blumer KJ. Mot3, a $\mathrm{Zn}$ finger transcription factor that modulates gene expression and attenuates mating pheromone signaling in Saccharomyces cerevisiae. Genetics 1998; 149:879-92; PMID:9611199.

68. Cipollina C, van den Brink J, Daran-Lapujade P, Pronk JT, Porro D, de Winde JH. Saccharomyces cerevisiae SFP1: at the crossroads of central metabolism and ribosome biogenesis. Microbiology 2008; 154:1686-99; PMID:18524923; DOI:10.1099/mic.0.2008/017392 0

69. Strawn LA, Lin CA, Tank EM, Osman MM, Simpson SA, True HL. Mutants of the Paf1 complex alter phenotypic expression of the yeast prion $\left[\mathrm{PSI}^{+}\right]$. Mol Biol Cell 2009; 20:2229-41; PMID:19225160; DOI:10.1091/ mbc.E08-08-0813. 